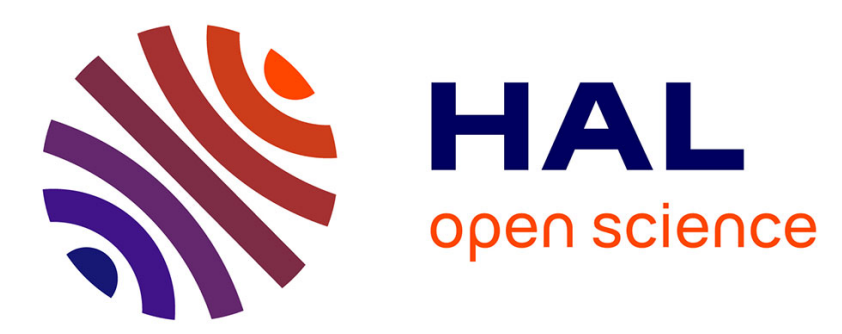

\title{
Analysis of ion implanted diamond-like-carbon films using laser-induced transient reflecting grating technique
}

\author{
Q. Shen, A. Harata, T. Sawada
}

\section{To cite this version:}

Q. Shen, A. Harata, T. Sawada. Analysis of ion implanted diamond-like-carbon films using laserinduced transient reflecting grating technique. Journal de Physique IV Proceedings, 1994, 04 (C7), pp.C7-233-C7-236. 10.1051/jp4:1994755 . jpa-00253284

\section{HAL Id: jpa-00253284 https://hal.science/jpa-00253284}

Submitted on 1 Jan 1994

HAL is a multi-disciplinary open access archive for the deposit and dissemination of scientific research documents, whether they are published or not. The documents may come from teaching and research institutions in France or abroad, or from public or private research centers.
L'archive ouverte pluridisciplinaire HAL, est destinée au dépôt et à la diffusion de documents scientifiques de niveau recherche, publiés ou non, émanant des établissements d'enseignement et de recherche français ou étrangers, des laboratoires publics ou privés. 


\title{
Analysis of ion implanted diamond-like-carbon films using laser-induced transient reflecting grating technique
}

\author{
Q. Shen, A. Harata and T. Sawada \\ Department of Industrial Chemistry, Faculty of Engineering, University of Tokyo, 7-3-1 Hongo, \\ Bunkyo-ku, Tokyo 113, Japan
}

\begin{abstract}
Laser-induced transient reflecting grating (TRG) technique was applied to measure both nitrogen-ion-implanted and nonimplanted thin-film coatings (thickness, $40 \mathrm{~nm}$ ) of diamond-like-carbon (DLC). Different TRG responses corresponding to the different samples with a variety of nitrogen-ion implantation doses were observed and the hypersonic surface acoustic wave velocities were obtained with a variety of wavelengths. A phenomenon was observed that the SAW velocity of the implanted DLC coating with higher dose became larger than that of the nonimplanted sample.
\end{abstract}

\section{INTRODUCTION}

The laser-induced transient reflecting grating (TRG) technique has proved to be a useful method for studying the optical, thermal and elastic properties of either bulk materials or films.[1,2,3] This technique is noncontact, nondestructive and has a high degree of spatial and temporal resolution as well as an excellent capability for generating high-power coherent ultrasonic waves ranging from a few megahertz to $30 \mathrm{GHz}$. On the other hand, diamond-like-carbon (DLC) films have recently attracted more and more interest because of their unique properties identical to those of diamond, such as high hardness, resistance to wear, chemical inertness, high electrical resistivity and thermal conductivity, next to excellent optical properties. These properties make DLC films useful for various optical, electronic and mechanical applications. For example, DLC thin films with about $20 \mathrm{~nm}$ thickness are expected to be used as protective overcoats for magnetic and optical recording discs.[4] Thus it is necessary and important to evaluate the practical properties of thin DLC coatings. However, to our knowledge, it is difficult to evaluate the characteristics of such a thin film by traditional methods. In this paper, we applied the TRG technique to study the characteristics of DLC thin-film coatings (40nm). Three kinds of samples with different nitrogen-ion doses and a nonimplanted sample were measured and different TRG responses were observed. It is shown that the characteristic properties of the DLC films with various ion doses, such as the elastic, thermal and optical properties, can be evaluated by this TRG technique.

\section{EXPERIMENTAL}

The TRG experimental arrangement is illustrated schematically in Fig. 1. A mode-locked Q-switch $\mathrm{Nd}$ :YAG laser is used. A single pulse is selected and doubled to produce an 84-ps pulse at a wavelength of $532 \mathrm{~nm}$ (i. e. second harmonic) and a repetition rate of $1 \mathrm{KHz}$. The laser beam is attenuated to less than $0.1 \mu \mathrm{J}$ per pulse to prevent the sample from being damaged and is split into three beams. Two of them, excitation pulses, are time coincident and cross at the sample surface to form an interference pattern with a grating spacing $\Lambda$, which is tunable by changing their crossing angle. Optical absorption 
of the sample and the following rapid nonradiative relaxation produce a spatially periodic, sinusoidal temperature distribution pattern with a spacing of $\Lambda$ which mimics the optical interference pattern. The temperature pattern induces elastic strain and generates counterpropagating coherent acoustic waves with a wavelength $\Lambda$ and a nonpropagating thermal pattern. Consequently, the acoustic waves and the thermal pattern induce a reflecting grating. The third laser pulse, which is temporally delayed by an optical delay line, relative to the excitation pulses, is then incident on the grating and is diffracted off the grating. The diffracted probe light is detected by a photomultiplier and its intensity is measured as a function of the time delay between the excitation and probe pulses, where the time delay is controlled by a computer. The diffracted signal can be used to monitor the grating dynamics, such as the acoustic oscillations and their decay, as well as the thermal diffusion.

\section{EXPERIMENTAL RESULTS AND DISCUSSION}

The samples measured were DLC films deposited by a chemical vapor deposition (CVD) technique on metallic multilayered substrates $(\mathrm{Co}(30 \mathrm{~nm}) / \mathrm{Cr}(150 \mathrm{~nm}) /$ plating of $\mathrm{Ni}$ and $\mathrm{P}$ alloy $(10 \mu \mathrm{m}))$. Ion beams with $10 \mathrm{KeV}$ energy and $68 \mathrm{~mA} / \mathrm{cm}^{2}$ current were used for nitrogen implantation in the DLC films with doses of $2 \times 10^{17}, 5 \times 10^{17}$, and $2 \times 10^{18}$ atoms $/ \mathrm{cm}^{2}$. Both the $\mathrm{N}^{+}$-ion-implanted samples and a nonimplanted sample were measured by this TRG technique with a variety of grating spacings. For the nonimplanted sample, the typical TRG responses with grating spacings of $0.86,1.3$ and $3.96 \mu \mathrm{m}$ are shown in Fig. 2. A single mode of surface acoustic wave (SAW), i. e. the Rayleigh-like mode, [3,5] was excited on the sample. As shown in Fig. 2, the TRG curves decayed faster as the grating spacing became smaller. This resulted from the fact that the signal decay caused by the heat flow in the grating direction, by equalizing the peak-to-null difference in temperature on the sample surface, became faster with decreasing grating spacing.[6] Thus the thermal diffusivity in the grating direction can be determined from the different decay times of the TRG curves corresponding to different grating spacings. With a $1.3 \mu \mathrm{m}$ grating spacing, the typical TRG responses for both the $\mathrm{N}^{+}$-ion-implanted samples with the different doses and the nonimplanted sample are shown in Fig. 3. It can be seen that the TRG responses of these samples varied with the implantation doses, i.e. the shapes of the waveforms, their relaxation times and SAW velocities. These results can be qualitatively understood; the bonding microstructure, the degree of lattice damages or disorders induced by the ion beams varied with the ion doses and the corresponding macroscopic properties such as the optical, thermal and acoustic properties also varied. In the present paper, changes of the SAW velocities of the DLC coatings versus the ion doses will be investigated.

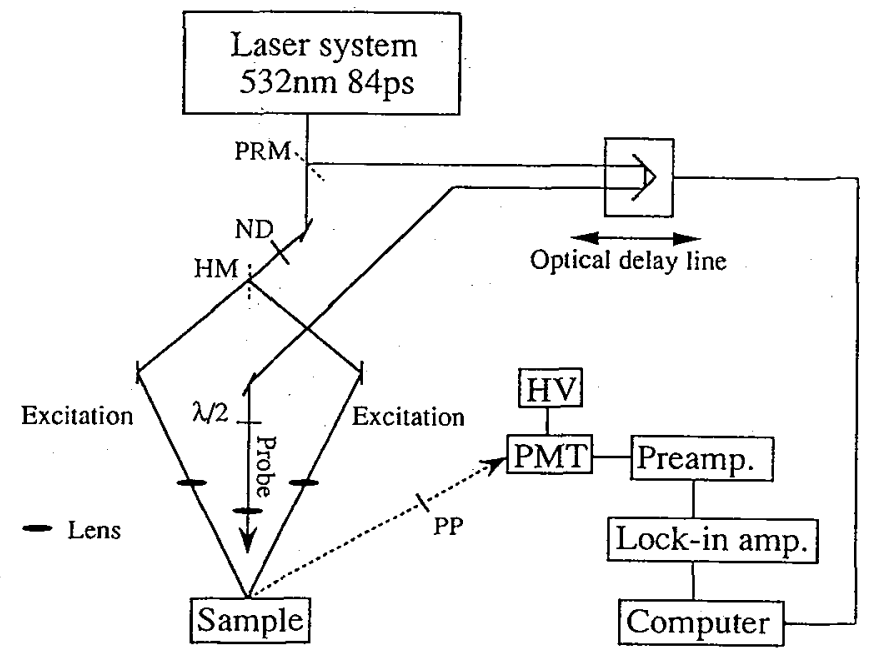

Fig. 1. Experimental arrangement of the laser-induced transient reflecting gratings. (HM) half mirror, (HV) high voltage, (ND) neutral density filter, (PRM) partial reflective mirror ( $R=10 \%)$, (PMT) photomultiplier, (PP) photopolarizer, and $(\lambda / 2)$ half-wave plate. 
The SAW velocities were extracted by fitting the experimental TRG curves to an empirical equation with a nonlinear least square method.[7] The SAW velocities with a variety of grating spacings for the four kinds of DLC coatings were obtained as shown in Fig. 4. It can be seen that the SAW velocity of each sample increases as the wavelength is decreased. From this result, higher sound velocities of the DLC coatings than the substrates can be expected. Especially, when the ion dose was $2 \times 10^{18}$ atoms $/ \mathrm{cm}^{2}$, the lattice of the DLC coating seemed to be hardened and the SAW velocity became larger than those of the other samples. Since the multilayered substrates were complicated, it was difficult to extract the elastic moduli of the DLC films by a method to make a good match between the experimental and the theoretical dispersion curves for a multilayered sample, which was reported elsewhere.[3] Thus an effective model was established for an approximation and the effective elastic moduli (Young's moduli) for the DLC coatings were determined by a semiquantitative study of changes in the elastic moduli by ion implantation, which will be reported in detail elsewhere.[8] It is shown that the effective Young's modulus of the ion-implanted sample is larger than that of the nonimplanted sample. From this result it follows that the DLC film with the implantation dose of $2 \times 10^{18}$ atoms $/ \mathrm{cm}^{2}$ became hardened. The reason for this phenomenon is not very clear yet and remains to be studied in greater detail. However, similar phenomena have been reported that nitrogen-ion-implanted steel became hard with higher doses.[9]

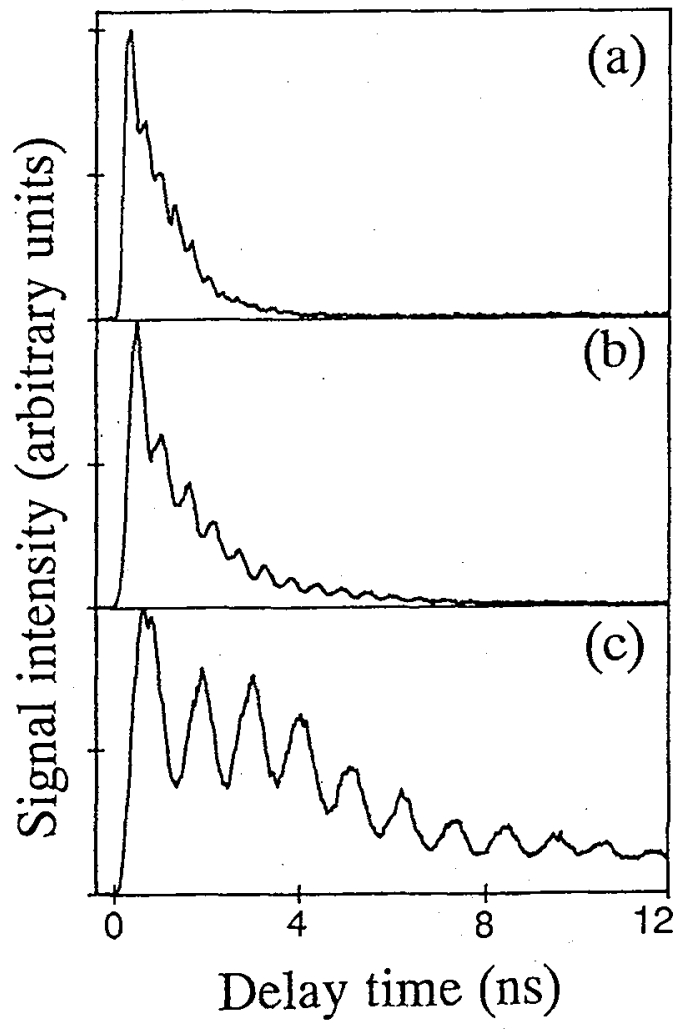

Fig. 2. Typical TRG responses of a nonimplanted DLC thin-film coating deposited on a $\mathrm{Co} / \mathrm{Cr} /$ plating of $\mathrm{Ni}$ and $\mathrm{P}$ multilayered substrate with (a) 0.86 , (b) 1.3 and (c) $3.96 \mu \mathrm{m}$ grating spacings.

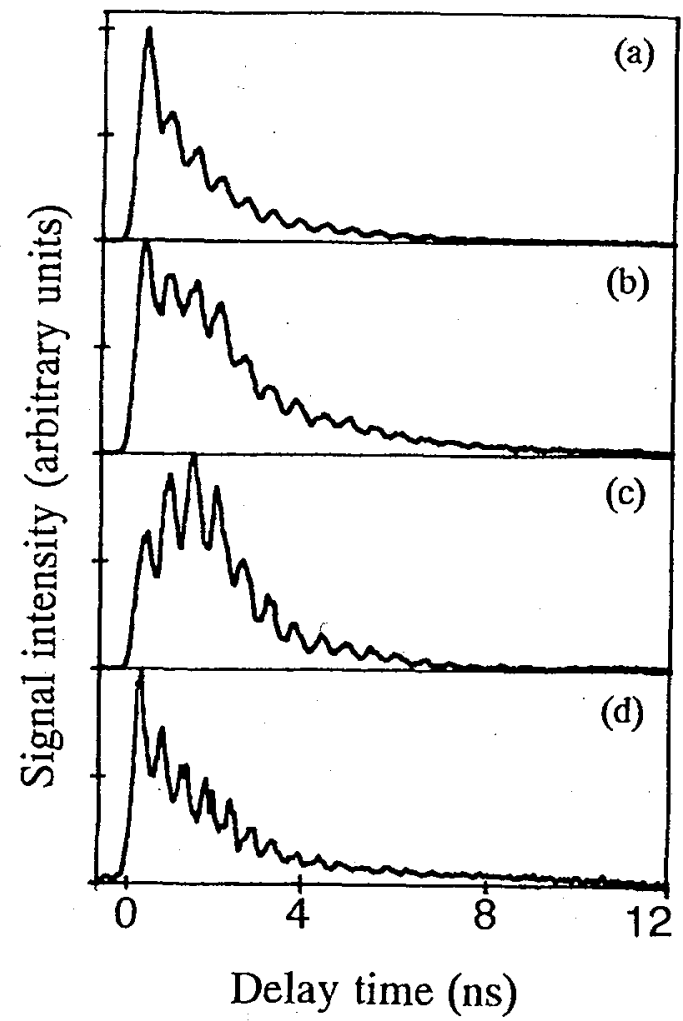

Fig. 3. Typical TRG responses of the nitrogen-ion-implanted DLC thinfilm coatings deposited on $\mathrm{Co} / \mathrm{Cr} /$ plating of $\mathrm{Ni}$ and $\mathrm{P}$ multilayered substrates with (b) $2 \times 10^{17}$, (c) $5 \times 10^{17}$, and (d) $2 \times 10^{18}$ atoms $/ \mathrm{cm}^{2}$ implantation doses and (a) a nonimplanted sample, with a $1.3 \mu \mathrm{m}$ grating spacing. 


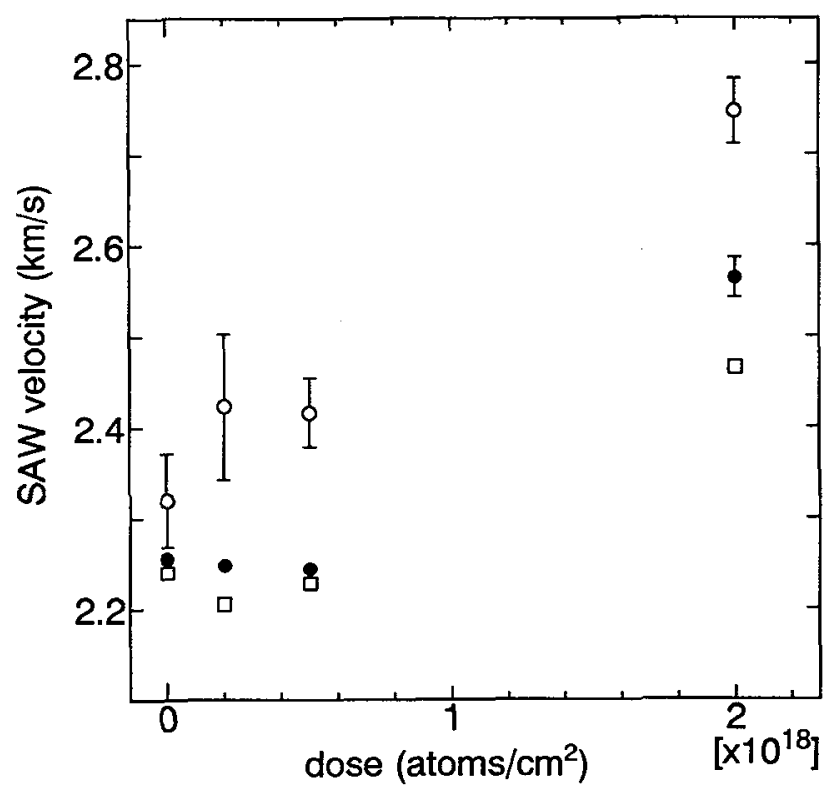

Fig.4. Phase velocities of SAWs observed by the TRG technique for the DLC thin-film coatings versus the nitrogen-ion implantation doses with a variety of grating spacings ( $00.86 \mu \mathrm{m}, \bullet 1.3 \mu \mathrm{m}$ and $\mathrm{a} 3.96 \mu \mathrm{m})$.

\section{SUMMARY}

The TRG technique was applied to study the characteristics of DLC thin-film coatings. Different TRG responses corresponding to nonimplanted and nitrogen-ion-implanted samples with various ion doses were observed and the corresponding SAW velocities with a variety of wavelengths were obtained. The SAW velocity of the nitrogen-ion-implanted DLC coating with dose of $2 \times 10^{18} \mathrm{atoms} / \mathrm{cm}^{2}$ was larger than that of the nonimplanted one, from which it was shown that the former became harder than the latter. The variation of the optical, thermal and elastic properties with the increasing ion doses and the corresponding lattice structures of the DLC films remains to be investigated quantitatively.

\section{REFERENCES}

[1] Harata A., Nishimura H. and Sawada T., Appl. Phys. Lett. 57 (1990) 132-134.

[2] Duggal A.R. and Nelson K.A., J. Chem. Phys. 94 (1991) 7677-7688.

[3] Shen Q., Harata A. and Sawada T., Jpn. J. Appl. Phys. 32 (1993) 3628-3632.

[4] Lettington A.H., Phil. Trans. R. Soc. Lond. A. 342 (1993) 287-296.

[5] Farnell G.W. and Adler E.L., in Physical Acoustics, Principles and Methods, eds. Mason M.P. and Thurston R.N. (Academic, New York, 1972) Vol. 9, 35-127.

[6] Marshall C.D., Fishman I.M., Dorfman R.C., Eom C.B. and Fayer M.D., Phys. Rev. B 45 (1992) 10009-10021.

[7] Harata A., Shen Q., Tanaka T. and Sawada T., Jpn. J. Appl. Phys. 32 (1993) 3633-3638.

[8] Shen Q., Harata A. and Sawada T., (to be published).

[9] Processing Technique of Materials, eds. Doyama M. and Yamamoto R. (Academic, Tokyo, 1987) 231-235 (in Japanese). 